\title{
Motor Neuron Diseases and Neuroprotective Peptides: A Closer Look to Neurons
}

\author{
Emanuela Zuccaro ${ }^{1,2,3+}$, Diana Piol ${ }^{1+}$, Manuela Basso ${ }^{4}$ and Maria Pennuto ${ }^{1,2,3 *}$ \\ ${ }^{1}$ Department of Biomedical Sciences, University of Padua, Padua, Italy, ${ }^{2}$ Veneto Institute of Molecular Medicine, Padua, \\ Italy, ${ }^{3}$ Padova Neuroscience Center, Padua, Italy, ${ }^{4}$ Department of Cellular, Computational and Integrative Biology - CIBIO, \\ University of Trento, Trento, Italy
}

Motor neurons (MNs) are specialized neurons responsible for muscle contraction that specifically degenerate in motor neuron diseases (MNDs), such as amyotrophic lateral sclerosis (ALS), spinal and bulbar muscular atrophy (SBMA), and spinal muscular atrophy (SMA). Distinct classes of MNs degenerate at different rates in disease, with a particular class named fast-fatigable MNs (FF-MNs) degenerating first. The etiology behind the selective vulnerability of FF-MNs is still largely under investigation. Among the different strategies to target MNs, the administration of protective neuropeptides is one of the potential therapeutic interventions. Pituitary adenylate cyclase-activating polypeptide (PACAP) is a neuropeptide with beneficial effects in many neurodegenerative diseases, including Alzheimer's disease, Parkinson's disease, and more recently SBMA. Another neuropeptide that has a neurotrophic effect on MNs is insulin-like growth factor 1 (IGF-1), also known as somatomedin C. These two peptides are implicated in the activation of neuroprotective pathways exploitable in the amelioration of pathological outcomes related to MNDs.

OPEN ACCESS

Edited by:

Nicola Ticozzi

University of Milan, Italy

Reviewed by:

Xavier Xifró,

University of Girona, Spain

Marina Boido,

University of Turin, Italy

${ }^{*}$ Correspondence:

Maria Pennuto

Maria.pennuto@unipd.it

†These authors have contributed equally to this work

Received: 11 June 2021

Accepted: 26 August 2021 Published: 17 September 2021

Citation:

Zuccaro E, Piol D, Basso M and Pennuto M (2021) Motor Neuron

Diseases and Neuroprotective

Peptides: A Closer Look to Neurons.

Front. Aging Neurosci. 13:723871.

doi: 10.3389/fnagi.2021.723871
Keywords: motor neuron (MN), IGF-1 (insulin-like growth factor 1), PACAP (pituitary adenylate cyclase-activating polypeptide), motor neuron disease (MND), ALS (Amyotrophic lateral sclerosis), spinobulbar muscular atrophy (SBMA), spinal muscular atrophy (SMA)

\section{INTRODUCTION}

The central nervous system (CNS) is populated by an incredible diversity of neuronal subtypes. Distinct neuron types are located in different parts of the organism and exhibit unique functions, depending on the very specific and finely controlled connectome (Molyneaux et al., 2009; Lodato and Arlotta, 2015). Furthermore, neurons of different types co-exist within the same region of the CNS and interplay to explicate high order functions, such as running, thinking or playing a piano (Finlay and Darlington, 1995). In the cerebral cortex, an astonishing diversity of excitatory glutamatergic projection neurons and inhibitory GABAergic interneurons, which release the gamma-aminobutyric acid neurotransmitter, have their specialized anatomy, morphology and physiology, and are coordinately assembled in a local microcircuitry (Markram et al., 2004; Molyneaux et al., 2005, 2009; Lodato et al., 2015). Likewise, the spinal cord is populated by multiple neuronal subtypes that have been classified over the last few decades according to their target and physiological properties. By the interplay of different neuron types, the motor system exhibits a vast range of activities, spanning from routine actions, such as walking or grasping, to more sophisticated movements, such as dancing or playing a piano (Hollyday et al., 1977; Landmesser and Pilar, 1978; Stifani, 2014). The establishment of the correct connections within the motor circuitry is critical for balanced electrical activity and motor function (Arber, 2012). Consequently, dysgenesis or dysfunction of the MN circuitry is associated with neurodegenerative 
and neuromuscular diseases, such as ALS, SBMA, and SMA. Although every year millions of people are diagnosed with highly debilitating and fatal neurodegenerative diseases, only few symptomatic treatments are currently available (Kanning et al., 2010). How this fine diversity in neuronal subtype identities and specific connectivity are assigned and what are the molecular logics underlying this process are still largely unknown, hampering the discovery of molecular candidates for treatment. In this review we describe the neuronal types affected in the most common forms of MNDs and the potential therapeutic strategies available based on the use of peptides with neuroprotective and neurotrophic effects.

\section{THE MOTOR SYSTEM}

The voluntary movement is controlled by a highly complex system named motor system (Figure 1). It consists of the pyramidal and extrapyramidal systems and is composed of upper motor neurons (UMNs), lower motor neurons (LMNs), and interneurons. The motor impulses originate in the UMNs, which are specialized neuronal cells that reside in the cerebral cortex and propagate through their long axons to the brainstem and spinal cord. Here, they synapse on LMNs, whose axons project out of the CNS to directly or indirectly control skeletal muscles in the periphery. Each MN residing in the spinal cord can synapse with multiple muscle fibers at the periphery. The MN and all the skeletal muscle fibers it innervates through its axonal terminals constitute the motor unit.

\section{UPPER MOTOR NEURONS (UMNs)}

UMNs are large pyramidal cells residing in the layer 5 of the cerebral cortex (Figure 1). They are responsible for the initiation of most voluntary movement by sending information down to the spinal cord through the corticospinal tract and directly activating interneurons or LMNs, which in turn signal on skeletal muscles for inhibiting or stimulating contraction, respectively. The direct pathway between the cerebral cortex and the brainstem/spinal cord is granted by the pyramidal tract, in contrast with extra-pyramidal tracts which provide indirect pathways for the coordination of movement. The UMNs of the pyramidal tract reside around the motor area of the cerebral cortex and, in general, innervate the musculature on the contralateral side of the body. Given the somatotopic organization of the motor area, UMNs controlling facial musculature are located on the most lateral area of the cerebral hemisphere, while control of the legs takes a more medial position, as represented in the cortical homunculus (Jang, 2014; Hooks et al., 2018). UMNs exert their effect via LMNs.

\section{LOWER MOTOR NEURONS (LMNS)}

LMNs can be hierarchically subdivided into different subtypes, based on their location in the brainstem and spinal cord, their physiological properties and specific targets (Figure 1). LMN classes are organized into groups reflecting both their origin and their function, and are further arranged into motor pools, where groups of LMNs are responsible for innervating a single skeletal muscle. Moreover, MNs belonging to the same motor pool can be subdivided into three distinct subgroups according to the type of fiber they innervate, namely alpha MNs $(\alpha M N)$, beta MNs $(\beta M N)$, and gamma MNs ( $\gamma \mathrm{MN})$ (Kanning et al., 2010). $\alpha \mathrm{MNs}$ innervate extrafusal muscle fibers and are the key of muscle contraction. They are characterized by a large soma, receive direct input from proprioceptive sensory afferents, and are the MN type that first undergoes dysfunction and degeneration in neurodegenerative diseases (NDDs). $\gamma \mathrm{MNs}$ innervate intrafusal muscle fibers and modulate the sensitivity of the muscle spindle. They have a smaller soma and do not exhibit any motor function, rather they modulate skeletal muscle contraction. Finally, $\beta M N s$ are characterized by a small soma and innervate both types of fibers. Being poorly abundant compared to the other two already mentioned subtypes, $\beta \mathrm{MNs}$ are a less well-defined population (Kanning et al., 2010).

All LMN classes differentiate from a unique pool of progenitors expressing the homeobox protein NK-6 homolog A (NKX6.1), paired box homeotic gene-6 (PAX6), and oligodendrocyte lineage transcription factor 2 (OLIG2) (Novitch et al., 2001; Vallstedt et al., 2001). Retinoic acid plays a central role in the diversification of MN subtypes and contributes to the spinal cord columnar organization (Lee et al., 2009). Nevertheless, very little is known about the molecular process of diversification of distinct MN subtypes. The first evidence of discrimination between $\alpha \mathrm{MN}$ and $\gamma \mathrm{MN}$ subtypes at embryonic stage came only few years ago, from a study pioneered by Ashrafi et al. (2012), where they demonstrated that the secreted signaling molecule Wingless-type MMTV integration site family member 7A (WNT7A) is selectively expressed in $\gamma \mathrm{MNs}$ in the mouse spinal cord by embryonic day E17.5 and continues to molecularly distinguish these two subtypes in early postmitotic neurons. Additionally, few postmitotic class-specific markers have been identified: the estrogen related receptor gamma (ERR3, ESRRG), GDNF family receptor alpha 1 (GFRA1), and the ATPase, $\mathrm{Na}^{+} / \mathrm{K}^{+}$transporting alpha1 (ATP1A1), have been shown to be selectively restricted to $\gamma \mathrm{MNs}$ during the first postnatal weeks (Friese et al., 2009; Shneider et al., 2009; Edwards et al., 2013), while high expression of the RNA binding protein NeuN (fox-1 homolog 3 or RBFOX3) is specific for $\alpha \mathrm{MN}$, becoming one of the few available criteria of distinction of these two broad MN classes (Friese et al., 2009).

The human body has more than 600 muscles, which work in a finely controlled and coordinated manner, enabling an incredible variety of behaviors. In order to maintain this coordination, $\alpha \mathrm{MNs}$ have to retain the characteristic of the type of fibers they innervate (Figure 1). In fact, depending on the type of innervated extrafusal fiber, $\alpha \mathrm{MNs}$ are further subdivided into three additional subtypes. Slow $\alpha \mathrm{MNs}$ innervate slow-twitch fatigue resistant fibers (SFR $\alpha \mathrm{MNs}$ ) and are characterized by an oxidative metabolism, whilst fast $\alpha \mathrm{MNs}$ target fast-twitch fastfatigable fibers ( $\mathrm{FF} \alpha \mathrm{MNs}$ ), which display a glycolytic metabolism, and fatigue-resistant fibers (FFR $\alpha \mathrm{MNs}$ ), which retain a level of oxidative capacity (Burke et al., 1973). Furthermore, SFR aMNs are small in size and fire regularly to control postural muscles, whereas low-excitable FF $\alpha \mathrm{MNs}$ are characterized by a large 


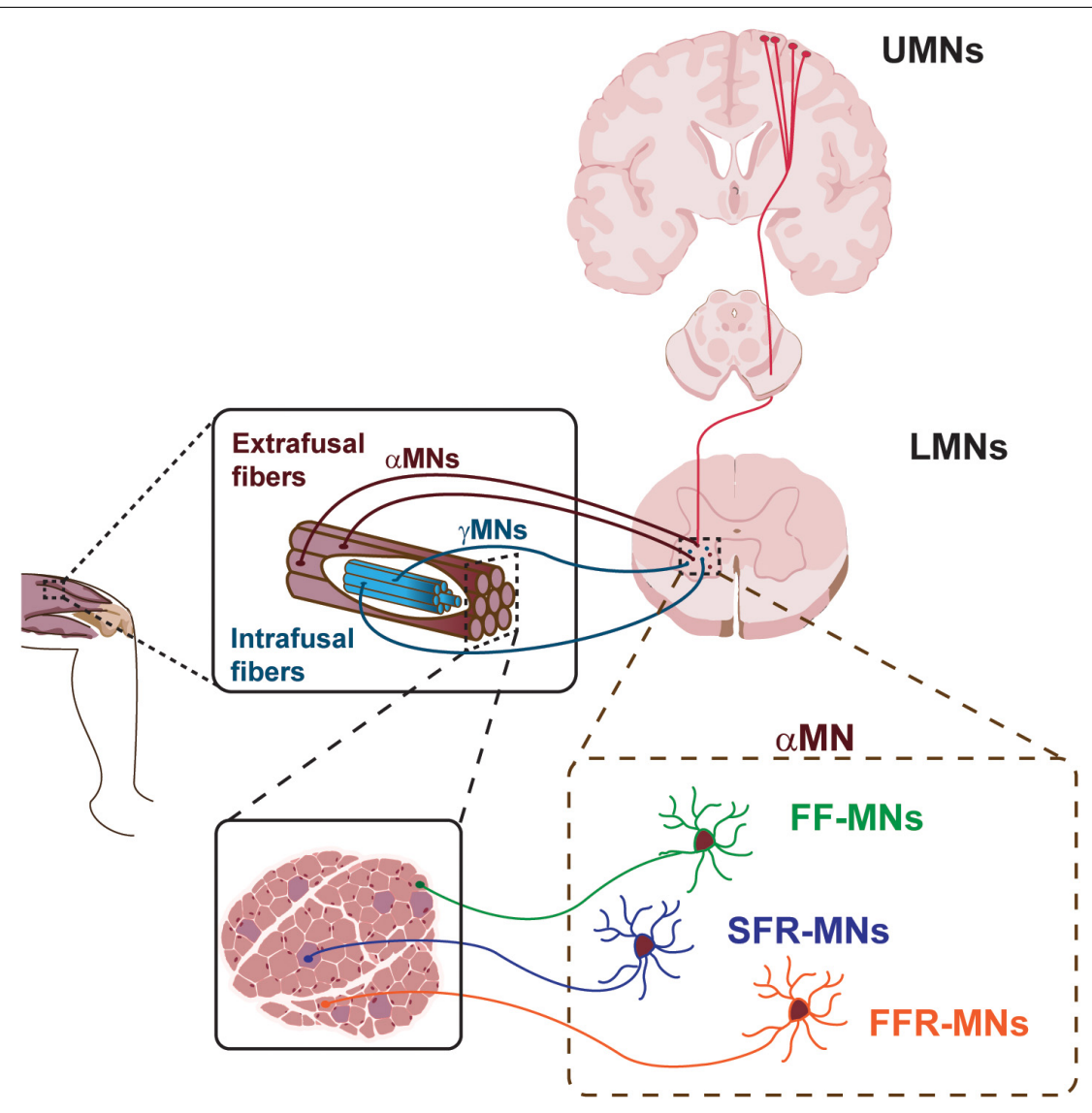

FIGURE 1 | Schematic of the motor system. Upper motor neurons (UMNs) project to lower motor neurons (LMNs) in the brainstem and spinal cord. LMNs innervate skeletal muscle fibers. Different classes of $\alpha-M N$ innervate diverse skeletal muscle fibers. FF-MNs, fast-fatigable MNs. SFR-MNs, slow fatigue resistant MNs.

FFR-MNs, fast fatigue resistant MNs.

soma and exert great force, yet for only a brief period of activity (Kanning et al., 2010; Duchateau and Enoka, 2011). Typically, one skeletal muscle contains all types of fibers innervated by their corresponding $\alpha \mathrm{MNs}$. However, the ratio between slow and fast fiber types varies between muscles, so as to suit each muscle's function. As the MNs themselves, also the motor unit can vary in size. SFR $\alpha M N$ s innervate few fibers, constituting a small motor unit, that in turn generates small force for a sustained muscle contraction. Large FF $\alpha \mathrm{MN}$ s can synapse with many fibers generating powerful and large motor units that ultimately enable massive contraction force, even if for a limited time. Finally, the motor unit composed of FFR $\alpha$ MNs display intermediate size and force generation. These differences in muscle fiber composition and contraction properties enable the execution of different functions and activities.

\section{KNOW THE TARGET: ADDRESS ALPHA MOTOR NEURON DIVERSITY TO TACKLE MNDS}

MNDs are characterized by the progressive dysfunction, degeneration and death of MNs. Although distinct MNDs have their own genetic and/or environmental cause, onset and prognosis, the vulnerability and consequent dysfunction and ultimately loss of MNs is a common denominator. MNDs can be classified into diseases primarily affecting either UMNs, LMNs, or both. ALS, also known as Lou Gehrig disease, is the most common late-onset MND characterized by the selective degeneration of both UMNs and LMNs. Most ALS cases are sporadic, and only $5-10 \%$ of ALS cases are considered to be familial. The disease manifests with progressive skeletal muscle weakness and atrophy, spasticity and fasciculation, finally leading to premature death. Primary lateral sclerosis (PLS) is a rare, idiopathic neuromuscular disease that often spontaneously occurs after the age of 50. It is characterized by the progressive weakness of voluntary movements as a result of the selective degeneration of UMNs, without impairment of LMNs. It is not a fatal disease, and individuals with PLS are treated only symptomatically. SMA involves the selective degeneration of LMNs, while no evidence of degeneration of UMNs has been reported. SMA is characterized by progressive muscle wasting that often results in early death. SBMA, also known as Kennedy's Disease, is a neuromuscular diseases characterized by loss of LMNs and skeletal muscle atrophy. SBMA fully manifests in males, with a disease onset ranging from 18 to 64 years of age. The 
slow progression of the disease does not lead to premature death, but affected subjects are at risk of choking on food and aspiration pneumonia because of weakness of the bulbar muscles.

Several studies report that there is a gradient of vulnerability to MNDs among distinct $\alpha \mathrm{MN}$ subtypes, with the low-excitable FF $\alpha M N$ class degenerating first (Nijssen et al., 2017). Why there is this kind of preferential susceptibility of FF $\alpha M N$ to MNDs and what are the molecular mechanisms driving this phenomenon are still largely unknown. Aimed to answer these questions, many efforts have been engaged by numerous groups, with the ultimate goal to shine the light on the key players and the molecular pathways involved in the divergence of $\alpha \mathrm{MN}$ classes. These works resulted in the identification of genes whose expression is enriched in a specific subtype, such as synaptic vesicle $2 \mathrm{a}$ (SV2A), and ESSRB for postnatal SFR $\alpha$ MNs (Chakkalakal et al., 2010; Enjin et al., 2010), and calcitonin-related polypeptide alpha (CALCA), chondrolectin (CHODL), the non-canonical Notch ligand delta-like homolog 1 (DLK1), and mmp-9 for FF $\alpha$ MNs (Enjin et al., 2010; Kaplan et al., 2014; Muller et al., 2014). These markers, along with the soma size, firing properties and excitability, were the only criteria of distinction between $\alpha \mathrm{MN}$ subtypes. Only recently, with the advent of single cell technology, MN diversity and subtype identity in the spinal cord is starting to be addressed, shading light on their unique transcriptomic profile (Delile et al., 2019; Alkaslasi et al., 2021; Blum et al., 2021). In particular, Blum et al. (2021) have profiled the transcriptome of 43,890 single-nuclei and identified distinct $\mathrm{MN}$ clusters in the autonomic and somatic motor system. In particular, they identified 16 subpopulations of sympathetic visceral MNs, including several clusters that localize to the sacral spinal cord, as well as a new skeletal MN population, which shares characteristics of the $\beta \mathrm{MNs}$ (Blum et al., 2021). Interestingly, Blum et al. (2021) deciphered the gene expression modules which define the differences between SFR, FFR, and FF MNs, using segmentation with known markers followed by hierarchical clustering. They identified novel transcriptional markers for FF and SFR populations, Kcnq5 and Prkcd, respectively, widening the molecular tools that can be exploited to study specifically $\alpha$-MN subpopulations. Alkaslasi et al. (2021) have further performed single-nucleus RNA sequencing of cholinergic neurons, revealing distinct subpopulations characterized by specific molecular profiles. Taken together, these studies have further our knowledge on the unique molecular profiles of $\mathrm{MN}$ subtypes, which is instrumental for disease study and modeling.

\section{LMN VULNERABILITY TO MNDS}

Both in mouse and human, there is a selective vulnerability of different subtypes of MNs, with specific populations being particularly affected and dying very early, whilst others surviving, even at late stages of the disease. Spinal MNs innervating skeletal muscles undergo progressive and massive dysfunction at early stages of disease, causing the gradual loss of nearly all voluntary movements. On the other hand, those neurons innervating specific facial muscles, such as extra-ocular muscles, are the last neurons to be affected. Moreover, it has been shown that eye movement and sexual functions remain relatively unimpaired in ALS patients, even at the final stages of the disease (Kanning et al., 2010). Given that many disease-triggering mutant proteins described to date, such as the androgen receptor (AR), superoxide dismutase 1 (SOD1), and TAR-DNA binding protein 43 (TDP43), are widely expressed in neurons and non-neuronal cells, the hypothesis that this selective vulnerability is due to their unique transcriptomic background has been largely investigated. Many groups have indeed focused their research on uncovering common patterns of selective protection or vulnerability in different MNDs, thereby identifying transcriptional changes between susceptible and resistant $\mathrm{MN}$ pools (Hedlund et al., 2010; Brockington et al., 2013; Kaplan et al., 2014). These efforts have led Kaplan et al. (2014) to elegantly show that the matrix metalloproteinase-9 (mmp-9) is strongly expressed in spinal MNs, while absent from oculomotor and Onuf's nuclei, becoming a therapeutic candidate for ALS treatment. This work underscores the importance of decoding the transcriptional landscapes of vulnerable and resistant MN subtypes, opening new perspectives in the identification of novel therapeutic targets. Decoding the mechanistic principles that shape neuronal diversity in spinal $\mathrm{MNs}$ is among the fundamental steps required to uncover the molecular substrates of the selective vulnerability underlying the pathogenesis of neurodegenerative diseases and to elaborate successful regenerative therapies in the near future.

\section{THERAPEUTIC STRATEGIES FOR MNDS}

To date, no effective cure is available to stop or reverse the progressive symptoms of MNDs. Patients receive supportive treatments to maintain their quality of life, such as physical rehabilitation to help muscles maintaining posture and slow atrophy. Moreover, few compounds have been successfully tested and approved for treatment of MNDs. Riluzole was for a long time the only approved drug from U. S. Food and Drug Administration (FDA) to treat ALS (Bensimon et al., 1994). This drug increases patient survival by $10 \%$ in clinical trials, probably protecting $\mathrm{MNs}$ by reducing the release of glutamate and blocking sodium channels. In 2017, the FDA approved Edavarone as therapeutic strategy to treat ALS. Edavarone is an antioxidant drug that slows disease progression measured through the evaluation of motor functions in patients (Writing Group; Edaravone (MCI-186) ALS 19 Study Group, 2017). For the treatment of SMA two drugs have been approved by FDA: Nusinersen and onasemnogene abeparvovecxioi. Nusinersen is an anti-sense oligonucleotide (ASO)-based treatment that affects the splicing of SMN2 gene, increasing full length SMN protein levels and ameliorating motor function (Passini et al., 2011; Hoy, 2017). Onasemnogene abeparvovecxioi is a later approved adeno-associated virus vector-based gene therapy that acts introducing a new copy of SMN1 gene in patients, stabilizing motor symptoms and improving walk capacity (Mendell et al., 2017). However, none of the mentioned therapeutic approaches is broadly applicable, thus justifying and encouraging ongoing research. 
Among the different therapeutic strategies under investigation to treat MNDs, the administration of neuroprotective peptides is an appealing approach that may address common molecular pathways dysregulated in the degenerating MNs (Table 1). Distinct MNDs have indeed distinct etiology, onset, manifestation, and progression. However, they also undergo common dysfunction that ultimately leads to neuronal degeneration, including protein misfolding and aggregation, proteostasis impairment, mitochondrial dysfunction, and gene expression dysregulation, as summarized in Figure 2 . In the next paragraphs, two neuropeptides with promising therapeutic potential in MNDs will be discussed, namely IGF-1 and PACAP (Figure 2).

\section{IGF-1: AN OLD FRIEND WITH NEUROPROTECTIVE EFFECTS}

IGF-1 is a small, single-chain polypeptide encoded by the IGF1 gene, localized on chromosome 12, and encoding a prepropeptide subsequently processed to produce the active peptide. IGF-1 has a structure similar to that of insulin, with a similarity of about $50 \%$, despite its diversified functions. In fact, IGF-1 is a member of the insulin-related peptide family, which also includes insulin and IGF-2. The human IGF-1 gene has 6 exons, by which several transcript variants are produced, leading to the generation of the mature 70-amino acid IGF-1 peptide (Oberbauer, 2013). In the brain, the proteolytic cleavage also gives rise to two additional active proteins: a 67-amino acid isoform lacking three amino acids at the $\mathrm{N}$-terminal of the protein, and the tripeptide cleavage product. IGF-1 binds to type I IGF receptor (IGF-IR), which belongs to the receptor tyrosine kinase (RTK) family, and shares about $60 \%$ sequence homology with the insulin receptor. The functional receptor is a dimer, which can also partner with insulin receptor. Two pathways are activated upon binding of IGF-1 to its receptor, the PI3K/Akt and the RAS/RAF/MAPK pathways, with mitogenic, antiapoptotic and transforming outcomes.

IGF-1 was first identified in 1957, when it was described as the "sulfation factor" induced in blood to act as mediator of growth hormone $(\mathrm{GH})$ effects in the rat cartilage (Salmon and Daughaday, 1957). IGF-1 is mainly expressed at all stages of development in the liver and is regulated by pulsatile pituitary $\mathrm{GH}$ secretion. Nevertheless, IGF-1 and its receptor are found to be expressed in all tissues, with autocrine and paracrine effects. In the central nervous system, IGF-1 and IGF-IR mRNA transcripts are both present in the grey matter, and the highest expression is seen in areas of high plasticity. IGF-1 was detected in E1415 rat neurons, with a peak at postnatal day 14 (Anlar et al., 1999). In the developing rat spinal cord, IGF-1 mRNA was detected in neurons, particularly of the cervicothoracic spinal cord (Rotwein et al., 1988). In the rat adult spinal cord, IGF-1 is detected in the ventral horn, sympathetic and dorsal root ganglia

TABLE 1 | Effects of PACAP and IGF-1 on motor neurons and their role in MNDs.

\begin{tabular}{|c|c|}
\hline Effects on motor neurons & References \\
\hline \multicolumn{2}{|l|}{ IGF-1 } \\
\hline Promotion of neuronal survival in vitro and in vivo & Ang et al., 1992; Hughes et al., 1993 \\
\hline Enhancing of axonal sprouting & Caroni and Grandes, 1990 \\
\hline Protection against excessive glutamate and ischemia & Nakao et al., 2001; Vincent et al., 2004 \\
\hline Induction of nerve regeneration & Kanje et al., 1989 \\
\hline Effects in MNDs & References \\
\hline Improved motor functions after intrathecal administration in ALS patients & Nagano et al., 2005 \\
\hline Improved muscle force, motor coordination and survival in SOD1-G93A ALS mice & Saenger et al., 2012; Wang et al., 2018 \\
\hline Reduction of MN degeneration and increase of neuromuscular junction innervation in a SMA mouse model & Tsai et al., 2014 \\
\hline Increased muscle fibers hypertrophy and the number of functionally active axonal sprouts in a SMA mouse model & Krieger et al., 2014 \\
\hline Improving of motor performances, attenuated weight loss and increased survival in a SBMA mouse model & Rinaldi et al., 2012 \\
\hline Amelioration of ionic current defects in a SBMA cell model & Jimenez Garduno et al., 2017 \\
\hline
\end{tabular}

Effects on neurons

References

PACAP

Promotion of neuronal survival

Dejda et al., 2011; Manecka et al., 2013

Induced in damaged neurons

Pettersson et al., 2014

Promotion of axonal regeneration

Tsuchida et al., 2014

Effects in MNDs

Neuroprotective action on preganglionic parasympathetic and sympathetic neurons in SOD1-G93A ALS mouse model Increase of cell survival in a ALS cell model

Attenuation of apoptotic signaling in ALS iPSC-derived MNs

MN protection in SBMA cell and mouse model

Amelioration of ionic current defects in a SBMA cell model

Ringer et al., 2013

Maugeri et al., 2019

Bonaventura et al., 2018

Polanco et al., 2016

Jimenez Garduno et al., 2017;

Martinez-Rojas et al., 2021 


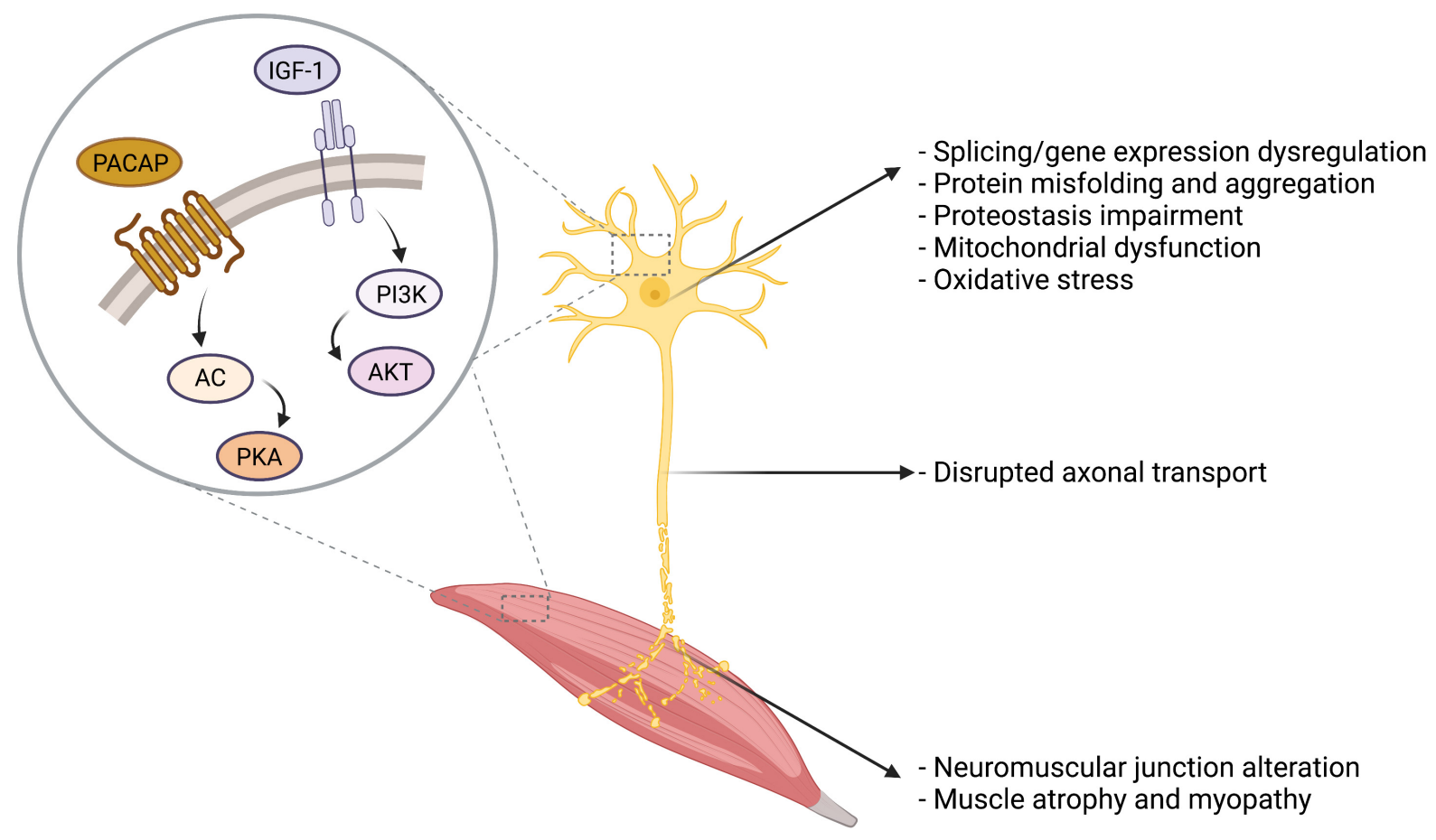

FIGURE 2 | Overview of the cellular and molecular alterations in MNDs. Several cellular and molecular alterations are common to distinct MNDs, including protein misfolding and aggregates, proteostasis impairment, oxidative stress, and mitochondrial dysfunction. IGF-1 and PACAP main signal transduction pathways are presented in the figure.

(Andersson et al., 1988). In a comparative study between normal and ALS patient adult spinal cords, IGF-1 quantitative receptor autoradiography revealed several IGF-1 binding sites. In normal human spinal cord high concentrations of IGF-1 binding sites were detected in the dorsal horn and central canal, intermediate levels in the ventral horn, intermediate zone, lamina $\mathrm{X}$ and tractus of Lissauer, while low levels were reported in dorsal, lateral and ventral white matter (Adem et al., 1994). Also, the IGF-1 immunoreactivity was detected in the same area of IGF-IR.

IGF-1 exerts neurotrophic properties in different regions of the CNS. Its early expression in fetal and adult CNS underlies its central role in neuronal development and trophic maintenance with both paracrine and autocrine mechanisms (D'Ercole et al., 1996). The importance of IGF-1 in CNS development was demonstrated with the generation of homozygous IGF-1 null mice, in which reduced brain size, altered myelination and loss of hippocampal granule and striatal parvalbumin-containing neurons were observed (Beck et al., 1995; Ye et al., 2002). Consistently with the phenotype of the IGF-1 knockout mice, the overexpression of IGF-1 leads to larger brain and increased myelination (Carson et al., 1993). Intuitively, GH production decreases with age, provoking a significant drop in IGF-1 levels in all tissues of the body, comprising the CNS, probably contributing with the decline in cognitive function (Muller et al., 2012; Toth et al., 2015). In MNs, IGF-1 promoted neuronal survival in vitro and in vivo in a facial axotomy model (Ang et al., 1992; Hughes et al., 1993). Moreover, IGF-1 enhanced MN axonal sprouting on skeletal muscle cells in vitro (Caroni and Grandes,
1990). IGF-1 has neuroprotective effects on MNs, protecting them against different insults, such as excessive glutamate and ischemia (Nakao et al., 2001; Vincent et al., 2004). In lesioned sciatic nerves, it was shown that IGF-1 induces regeneration (Kanje et al., 1989). IGF-1 mRNA levels increase distal to the site of crush and decrease after axonal regeneration, suggesting a role for IGF-1 in the regenerative processes (Glazner et al., 1994).

\section{ROLE OF IGF-1 IN MNDs}

Given its neuroprotective properties, IGF-1 has been extensively investigated as potential therapeutic for neurodegenerative diseases (Bryan and Bowman, 2017; Yang et al., 2018). Several studies have explored the potential therapeutic effect of IGF-1 in MNDs. In ALS, recombinant human IGF-1 (rh-IGF-1) entered two randomized double-blind placebo-controlled clinical trials (Lai et al., 1997; Borasio et al., 1998). In these clinical trials, rh-IGF-1 was administered subcutaneously for 9 months with no appreciable effects on ALS patients. Posterior meta-analysis studies revealed that $\mathrm{rh}$-IGF-1 administration was beneficial with low evidence, without an improvement in survival (Beauverd et al., 2012). In another clinical trial subcutaneously injected hrIGF-1 revealed no difference in primary or secondary outcomes, defined as manual muscle testing score and tracheostomy-free survival and ALS functional rating scale, respectively (Sorenson et al., 2008). The meta-analysis study by Beauverd et al. (2012) confirmed the lack of differences between placebo and 
rh-IGF-1-treated patients in all the outcomes in this clinical trial. In 2005, a double-blind clinical trial was performed to assess the effect of intrathecal administration of IGF-1 in 9 patients with ALS, revealing a positive effect in motor functions without any variations in vital capacity (Nagano et al., 2005). Taken together, the results of these clinical trials suggest the use of routes of administrations that circumvent the limitations of IGF-1 bioavailability and the need for further data derived from pre-clinical studies. In SOD1-G93A mice, a polyethylene glycol-modified IGF-1 was systemically administered, obtaining encouraging results on muscle force, motor coordination and survival of the milder phenotype line (Saenger et al., 2012). Wang et al. (2018) used the same ALS mouse model to conduct a preclinical study systemically administering the animals with adenoassociated virus (AAV) expressing IGF-1, finding a consistent improvement of survival.

IGF-1 therapeutic potential has also been tested in SMA. In a severe mouse model of SMA, the intravenous administration of AAV vectors encoding hr-IGF-1 at postnatal day 1 reduced MN degeneration and increased innervation at the neuromuscular junction after 7 days, and it prolonged the mouse survival (Tsai et al., 2014). Importantly, this approach increased survival of motor neuron (SMN) expression levels in spinal cord, brain and muscles. In a SMA mouse model with respiratory distress type 1 , subcutaneous administration of IGF-1 increased muscle fibers hypertrophy and the number of functionally active axonal sprouts, without any effect on MN survival (Krieger et al., 2014). These studies suggest that IGF-1 is a promising adjuvant therapeutic route for SMA patients, but more experimental evidence needs to be provided.

The role of IGF-1 in SBMA pathogenesis was first investigated because of the ability of this molecule to activate the PI3K-AKT pathway (Palazzolo et al., 2007). AKT-dependent phosphorylation of serines 215 and 792 on polyglutamineexpanded androgen receptor impeded ligand binding, improving cell survival in MN-derived cells modeling SBMA. Thus, in this preliminary study, IGF-1 had beneficial effects on toxicity induced by the mutant protein. Muscle-specific IGF-1 overexpression in SBMA transgenic mice rescued behavioral and histopathological abnormalities, extending lifespan, through the induction of AKT-dependent polyglutamine-expanded androgen receptor protective phosphorylation (Palazzolo et al., 2009). To translate these findings into a possible treatment, a preclinical study was performed on transgenic SBMA mice, injecting intraperitoneally rh-IGF-1. The treatment improved motor performances, attenuated weight loss and increased survival (Rinaldi et al., 2012). The encouraging outcomes in this pre-clinical study provided the rationale for a doubleblind, randomized, placebo-controlled, multicenter clinical trial in which 24 patients were injected intravenously with IGF1 or placebo (Grunseich et al., 2018). This phase II clinical trials showed that IGF-1 administration preserved thigh muscle volume of SBMA patients, but did not affect muscle strength or function, suggesting the potential of IGF-1 with the need to deepen the study of its effects. Possibly, a combined treatment of IGF-1 together with an anti-androgen, such as leuprorelin (Banno et al., 2009), may enhance the potential of both approaches to either arrest or at least delay disease progression. Consistent with their neuroprotective effects, both IGF-1 and PACAP ameliorated ionic current defects in a cell model of SBMA (Jimenez Garduno et al., 2017; Martinez-Rojas et al., 2021). The promising therapeutic effects of these peptides may ultimately contribute to therapy development for MNDs.

\section{PACAP AS A PROMISING THERAPEUTIC STRATEGY FOR MNDs}

Among the neuropeptide gene superfamily, PACAP belongs to the glucagon/secretin gene family, together with glucagon, secretin, vasoactive intestinal peptide, growth hormone releasing hormone, and gastric inhibitory peptide genes (Soles-Tarres et al., 2020). PACAP is synthetized by ADCYAP1 gene as preproPACAP peptide precursor, which is then processed through proteolytic cleavage that gives origin to several active peptides, including PACAP-38 and PACAP-27 (Miyata et al., 1989). PACAP is the ligand of three heterotrimeric $\mathrm{G}$ protein-coupled receptors, namely ADCYAP Receptor Type 1 (PAC1), Vasoactive Intestinal Peptide Receptor 1 (VPAC1), and Vasoactive Intestinal Peptide Receptor 2 (VPAC2). The stimulation of these receptors leads mainly to activation of adenylyl cyclase (AC)/protein kinase A (PKA) signaling, but other cAMP-dependent pathways may play important roles in the downstream effects of PACAP (Zhou et al., 1999; Ster et al., 2007; Juhasz et al., 2015). PACAP was first identified in Miyata et al. (1989) as a regulatory peptide that increases AC activity in the anterior pituitary cells, observation from which they coined its name. Nevertheless, thirty years of studies revealed that PACAP is broadly expressed in the central nervous system as well as in peripheral tissues. In the rat spinal cord, PACAP mRNA is detected as early as E14 (Jaworski and Proctor, 2000), while in the adult mouse it is expressed in lamina 1 of the dorsal horn of the spinal cord, and in the lateral gray column (Condro et al., 2016). In addition, its expression was also detected in the human adult spinal cord in the dorsal and ventral horn, and especially in the thoracic segments in the lateral funiculus projecting into the intermediolateral cell column (Dun et al., 1996). These observations suggest that PACAP is involved in sensory and autonomic pathways. PAC1, VPAC1, and VPAC2 receptors are widely expressed in the central nervous system. The most studied receptor is PAC1, the only PACAP-specific receptor. PAC1 is expressed in the spinal cord starting from E14 through E18 (Jaworski and Proctor, 2000). Other studies revealed that both PAC1 and VPAC1 receptors are consistently expressed in MNs of the rat facial motor nuclei (Zhou et al., 1999), while VPAC2 has been recently shown to be expressed in $\alpha$ MNs (Blum et al., 2021). PACAP has been shown to bind with high affinity to PAC1 and VPAC2 receptors, promoting dendritic outgrowth of cortical neurons.

In the central nervous system, PACAP has a plethora of functions in development, aging and regeneration. It regulates neurite outgrowth (Ogata et al., 2015), neuropeptide and neurotransmitter production (Stroth et al., 2013) and, importantly, neuronal survival (Dejda et al., 2011; Manecka et al., 2013). Among the different PACAP functions, the ability 
to induce neuroprotection is well-studied in several fields, from neuroinflammation to neurodegeneration. In a model of peripheral nerve injury, PACAP is extensively induced in the damaged neurons and triggers the activation of neuroprotective pathways (Pettersson et al., 2014). Fang et al. (2010) analyzed the effect of PACAP administration in combination with mesenchymal stem cells in rats subjected to spinal cord injury, demonstrating a therapeutic potential for this neuropeptide. The beneficial effect of PACAP was also confirmed in another mouse model of spinal cord injury, highlighting that the neuropeptide may improve motor functions with the induction of axonal regeneration (Tsuchida et al., 2014).

\section{ROLE OF PACAP IN MNDS}

PACAP effects were deeply investigated in NDDs, such as Parkinson's disease and Alzheimer's disease (Rat et al., 2011; Han et al., 2014; Maasz et al., 2017), as well as MNDs. In a widely used transgenic mouse model of ALS expressing SOD1 carrying the ALS-linked mutation, glycine 93 substitution to alanine (G93A), PACAP exhibits a neuroprotective action on vulnerable neurons. In particular, it has been reported that the genetic depletion of PACAP in SOD1-G93A mice led to a loss of preganglionic parasympathetic and sympathetic neurons-which normally constitutively express PACAP-while sparing somatomotor neurons, indicating that PACAP has a neuroprotective role on visceromotor neurons in ALS (Ringer et al., 2013). Moreover, in an in vitro model of ALS, PACAP treatment increased cell survival through the activation of PKA/EGFR/MMP-2 axis (Maugeri et al., 2019), while in motor cortex of ALS patients, PACAP and its receptor PAC1 mRNA levels were dysregulated (Bonaventura et al., 2018). In line with the emerging role of PACAP in MN survival, it has been reported that PACAP treatment attenuated apoptotic signaling activated in human induced pluripotent stem cells (iPSC)-derived MNs following starvation. Of note, PACAP has also been recently shown to attenuate SBMA phenotype in in vitro and in vivo models, implying that the neuroprotective effects of this neuropeptide extend to different types of neurological conditions involving the motor system. In the case of SBMA, PACAP activated a signaling pathway that ultimately resulted in the dephosphorylation of the disease-causing protein, polyglutamine-expanded AR, thus enhancing its degradation, leading to $\mathrm{MN}$ protection (Polanco et al., 2016). In a preclinical study, a novel potent

\section{REFERENCES}

Adem, A., Ekblom, J., Gillberg, P. G., Jossan, S. S., Hoog, A., Winblad, B., et al. (1994). Insulin-like growth factor-1 receptors in human spinal cord: changes in amyotrophic lateral sclerosis. J. Neural Transm. Gen. Sect. 97, 73-84. doi: $10.1007 /$ bf01277964

Alkaslasi, M. R., Piccus, Z. E., Hareendran, S., Silberberg, H., Chen, L., Zhang, Y., et al. (2021). Single nucleus RNA-sequencing defines unexpected diversity of cholinergic neuron types in the adult mouse spinal cord. Nat. Commun. 12:2471. doi: 0.1038/s41467-021-22 $691-2$ and stable PACAP analog was administered to SBMA knock-in mice at disease onset, improving life expectancy and motor performances, which correlated with decreased mutant protein phosphorylation and accumulation (Polanco et al., 2016). In addition, the PACAP analog rescued SBMA-induced mitochondrial membrane depolarization in patient-derived neuroprogenitor cells, consolidating the therapeutic potential of PACAP and its derivatives. Moreover, electrophysiological phenotypes were investigated in SBMA MN-derived cells (Jimenez Garduno et al., 2017). Altered ionic currents were recorded in $\mathrm{MN}$-derived cells expressing polyglutamineexpanded androgen receptor, and those abnormalities were partially rescued by PACAP treatment. These insights highlight a possible therapeutic application for PACAP in MNDs, such as ALS and SBMA.

Taken together, knowledge on the unique features of distinct types of neurons differentially vulnerable to MNDs is crucial for the development of novel therapeutic strategies and to deeply understand the mechanisms of neuroprotection of already developed drugs.

\section{AUTHOR CONTRIBUTIONS}

MP and EZ coordinated the work, wrote the manuscript, and provided the funding. $\mathrm{DP}$ and $\mathrm{MB}$ wrote and revised the manuscript. All authors contributed to the article and approved the submitted version.

\section{FUNDING}

This work was supported by the Fondazione Telethon (GGP19128 to MP), Association Française contre les Myopathies (22221 to MP and MB), PRIN-MIUR Italy (2017F2A2C5 to MP), PROGRAM RARE DISEASES CNCCS-Scarl-Pomezia (to MP), Fondazione JUST ITALIA (to MP), Kennedy's Disease Association Research Grant (to EZ), Akira Arimura Foundation (to EZ), Fondazione Umberto Veronesi Fellowship (to EZ), and Horizon 2020 under the MSCA Individual Fellowship panel (MOVEMent-846282 to EZ).

\section{ACKNOWLEDGMENTS}

Figures were created with BioRender.com.

Andersson, I. K., Edwall, D., Norstedt, G., Rozell, B., Skottner, A., and Hansson, H. A. (1988). Differing expression of insulin-like growth factor I in the developing and in the adult rat cerebellum. Acta Physiol. Scand. 132, 167-173. doi: 10.1111/j.1748-1716.1988.tb08314.x

Ang, L. C., Bhaumick, B., Munoz, D. G., Sass, J., and Juurlink, B. H. (1992). Effects of astrocytes, insulin and insulin-like growth factor I on the survival of motoneurons in vitro. J. Neurol. Sci. 109, 168-172. doi: 10.1016/0022-510x(92) 90164-g

Anlar, B., Sullivan, K. A., and Feldman, E. L. (1999). Insulin-like growth factorI and central nervous system development. Horm. Metab. Res. 31, 120-125. doi: $10.1055 /$ s-2007-978708 
Arber, S. (2012). Motor circuits in action: specification, connectivity, and function. Neuron 74, 975-989. doi: 10.1016/j.neuron.2012.05. 011

Ashrafi, S., Lalancette-Hebert, M., Friese, A., Sigrist, M., Arber, S., Shneider, N. A., et al. (2012). Wnt7A identifies embryonic gamma-motor neurons and reveals early postnatal dependence of gamma-motor neurons on a muscle spindlederived signal. J. Neurosci. 32, 8725-8731. doi: 10.1523/jneurosci.1160-12. 2012

Banno, H., Katsuno, M., Suzuki, K., Takeuchi, Y., Kawashima, M., Suga, N., et al. (2009). Phase 2 trial of leuprorelin in patients with spinal and bulbar muscular atrophy. Ann. Neurol. 65, 140-150.

Beauverd, M., Mitchell, J. D., Wokke, J. H., and Borasio, G. D. (2012). Recombinant human insulin-like growth factor I (rhIGF-I) for the treatment of amyotrophic lateral sclerosis/motor neuron disease. Cochrane Database Syst. Rev. 11:CD002064. doi: 10.1002/14651858.CD002064.pub3

Beck, K. D., Powell-Braxton, L., Widmer, H. R., Valverde, J., and Hefti, F. (1995). IGF-1 gene disruption results in reduced brain size, CNS hypomyelination, and loss of hippocampal granule and striatal parvalbumin-containing neurons. Neuron 14, 717-730. doi: 10.1016/0896-6273(95)90216-3

Bensimon, G., Lacomblez, L., and Meininger, V. (1994). A controlled trial of riluzole in amyotrophic lateral sclerosis. ALS/riluzole study group. N. Engl. J. Med. 330, 585-591. doi: 10.1056/NEJM199403033300901

Blum, J. A., Klemm, S., Shadrach, J. L., Guttenplan, K. A., Nakayama, L., Kathiria, A., et al. (2021). Single-cell transcriptomic analysis of the adult mouse spinal cord reveals molecular diversity of autonomic and skeletal motor neurons. Nat. Neurosci. 24, 572-583. doi: 10.1038/s41593-020-00795-0

Bonaventura, G., Iemmolo, R., D’Amico, A. G., La Cognata, V., Costanzo, E., Zappia, M., et al. (2018). PACAP and PAC1R are differentially expressed in motor cortex of amyotrophic lateral sclerosis patients and support survival of iPSC-derived motor neurons. J. Cell. Physiol. 233, 3343-3351. doi: 10.1002/jcp. 26182

Borasio, G. D., Robberecht, W., Leigh, P. N., Emile, J., Guiloff, R. J., Jerusalem, F., et al. (1998). A placebo-controlled trial of insulin-like growth factor-I in amyotrophic lateral sclerosis. European ALS/IGF-I study group. Neurology 51, 583-586. doi: 10.1212/wnl.51.2.583

Brockington, A., Ning, K., Heath, P. R., Wood, E., Kirby, J., Fusi, N., et al. (2013). Unravelling the enigma of selective vulnerability in neurodegeneration: motor neurons resistant to degeneration in ALS show distinct gene expression characteristics and decreased susceptibility to excitotoxicity. Acta Neuropathol. 125, 95-109. doi: 10.1007/s00401-012-1058-5

Bryan, M. R., and Bowman, A. B. (2017). Manganese and the insulin-IGF signaling network in Huntington's disease and other neurodegenerative disorders. Adv. Neurobiol. 18, 113-142. doi: 10.1007/978-3-319-60189-2_6

Burke, R. E., Levine, D. N., Tsairis, P., and Zajac, F. E. III (1973). Physiological types and histochemical profiles in motor units of the cat gastrocnemius. J. Physiol. 234, 723-748. doi: 10.1113/jphysiol.1973.sp010369

Caroni, P., and Grandes, P. (1990). Nerve sprouting in innervated adult skeletal muscle induced by exposure to elevated levels of insulin-like growth factors. J. Cell Biol. 110, 1307-1317. doi: 10.1083/jcb.110.4.1307

Carson, M. J., Behringer, R. R., Brinster, R. L., and McMorris, F. A. (1993). Insulin-like growth factor I increases brain growth and central nervous system myelination in transgenic mice. Neuron 10, 729-740. doi: 10.1016/08966273(93)90173-o

Chakkalakal, J. V., Nishimune, H., Ruas, J. L., Spiegelman, B. M., and Sanes, J. R. (2010). Retrograde influence of muscle fibers on their innervation revealed by a novel marker for slow motoneurons. Development 137, 3489-3499. doi: 10.1242/dev.053348

Condro, M. C., Matynia, A., Foster, N. N., Ago, Y., Rajbhandari, A. K., Van, C., et al. (2016). High-resolution characterization of a PACAP-EGFP transgenic mouse model for mapping PACAP-expressing neurons. J. Comp. Neurol. 524, 3827-3848. doi: 10.1002/cne.24035

Dejda, A., Seaborn, T., Bourgault, S., Touzani, O., Fournier, A., Vaudry, H., et al. (2011). PACAP and a novel stable analog protect rat brain from ischemia: insight into the mechanisms of action. Peptides 32, 1207-1216. doi: 10.1016/ j.peptides.2011.04.003

Delile, J., Rayon, T., Melchionda, M., Edwards, A., Briscoe, J., and Sagner, A. (2019). Single cell transcriptomics reveals spatial and temporal dynamics of gene expression in the developing mouse spinal cord. Development 146:dev173807.
D’Ercole, A. J., Ye, P., Calikoglu, A. S., and Gutierrez-Ospina, G. (1996). The role of the insulin-like growth factors in the central nervous system. Mol. Neurobiol. $13,227-255$.

Duchateau, J., and Enoka, R. M. (2011). Human motor unit recordings: origins and insight into the integrated motor system. Brain Res. 1409, 42-61. doi: 10.1016/j.brainres.2011.06.011

Dun, N. J., Miyazaki, T., Tang, H., and Dun, E. C. (1996). Pituitary adenylate cyclase activating polypeptide immunoreactivity in the rat spinal cord and medulla: implication of sensory and autonomic functions. Neuroscience 73, 677-686. doi: 10.1016/0306-4522(96)00057-7

Edwards, I. J., Bruce, G., Lawrenson, C., Howe, L., Clapcote, S. J., Deuchars, S. A., et al. (2013). Na+/K+ ATPase alphal and alpha3 isoforms are differentially expressed in alpha- and gamma-motoneurons. J. Neurosci. 33, 9913-9919. doi: 10.1523/jneurosci.5584-12.2013

Enjin, A., Rabe, N., Nakanishi, S. T., Vallstedt, A., Gezelius, H., Memic, F., et al. (2010). Identification of novel spinal cholinergic genetic subtypes disclose Chodl and Pitx 2 as markers for fast motor neurons and partition cells. J. Comp. Neurol. 518, 2284-2304.

Fang, K. M., Chen, J. K., Hung, S. C., Chen, M. C., Wu, Y. T., Wu, T. J., et al. (2010). Effects of combinatorial treatment with pituitary adenylate cyclase activating peptide and human mesenchymal stem cells on spinal cord tissue repair. PLoS One 5:e15299. doi: 10.1371/journal.pone.0015299

Finlay, B. L., and Darlington, R. B. (1995). Linked regularities in the development and evolution of mammalian brains. Science 268, 1578-1584. doi: 10.1126/ science. 7777856

Friese, A., Kaltschmidt, J. A., Ladle, D. R., Sigrist, M., Jessell, T. M., and Arber, S. (2009). Gamma and alpha motor neurons distinguished by expression of transcription factor Err3. Proc. Natl. Acad. Sci. U.S.A. 106, 13588-13593. doi: 10.1073/pnas.0906809106

Glazner, G. W., Morrison, A. E., and Ishii, D. N. (1994). Elevated insulin-like growth factor (IGF) gene expression in sciatic nerves during IGF-supported nerve regeneration. Brain Res. Mol. Brain Res. 25, 265-272. doi: 10.1016/0169$328 \mathrm{x}(94) 90162-7$

Grunseich, C., Miller, R., Swan, T., Glass, D. J., Mouelhi, M. E., Fornaro, M., et al. (2018). Safety, tolerability, and preliminary efficacy of an IGF-1 mimetic in patients with spinal and bulbar muscular atrophy: a randomised, placebocontrolled trial. Lancet Neurol. 17, 1043-1052. doi: 10.1016/S1474-4422(18) 30320-X

Han, P., Tang, Z., Yin, J., Maalouf, M., Beach, T. G., Reiman, E. M., et al. (2014). Pituitary adenylate cyclase-activating polypeptide protects against beta-amyloid toxicity. Neurobiol. Aging 35, 2064-2071. doi: 10.1016/j.neurobiolaging.2014. 03.022

Hedlund, E., Karlsson, M., Osborn, T., Ludwig, W., and Isacson, O. (2010). Global gene expression profiling of somatic motor neuron populations with different vulnerability identify molecules and pathways of degeneration and protection. Brain 133(Pt 8), 2313-2330. doi: 10.1093/brain/ awq167

Hollyday, M., Hamburger, V., and Farris, J. M. (1977). Localization of motor neuron pools supplying identified muscles in normal and supernumerary legs of chick embryo. Proc. Natl. Acad. Sci. U.S.A. 74, 3582-3586. doi: 10.1073/pnas. 74.8.3582

Hooks, B. M., Papale, A. E., Paletzki, R. F., Feroze, M. W., Eastwood, B. S., Couey, J. J., et al. (2018). Topographic precision in sensory and motor corticostriatal projections varies across cell type and cortical area. Nat. Commun. 9:3549. doi: 10.1038/s41467-018-06928-1

Hoy, S. M. (2017). Nusinersen: first global approval. Drugs 77, 473-479. doi: 10.1007/s40265-017-0711-7

Hughes, R. A., Sendtner, M., and Thoenen, H. (1993). Members of several gene families influence survival of rat motoneurons in vitro and in vivo. J. Neurosci. Res. 36, 663-671.

Jang, S. H. (2014). The corticospinal tract from the viewpoint of brain rehabilitation. J. Rehabil. Med. 46, 193-199. doi: 10.2340/16501977-1782

Jaworski, D. M., and Proctor, M. D. (2000). Developmental regulation of pituitary adenylate cyclase-activating polypeptide and $\mathrm{PAC}(1)$ receptor mRNA expression in the rat central nervous system. Brain Res. Dev. Brain Res. 120, 27-39. doi: 10.1016/s0165-3806(99)00192-3

Jimenez Garduno, A. M., Juarez-Hernandez, L. J., Polanco, M. J., Tosatto, L., Michelatti, D., Arosio, D., et al. (2017). Altered ionic currents and amelioration 
by IGF-1 and PACAP in motoneuron-derived cells modelling SBMA. Biophys. Chem. 229, 68-76. doi: 10.1016/j.bpc.2017.05.003

Juhasz, T., Szentleleky, E., Somogyi, C. S., Takacs, R., Dobrosi, N., Engler, M., et al. (2015). Pituitary adenylate cyclase activating polypeptide (PACAP) pathway is induced by mechanical load and reduces the activity of hedgehog signaling in chondrogenic micromass cell cultures. Int. J. Mol. Sci. 16, 17344-17367. doi: 10.3390/ijms160817344

Kanje, M., Skottner, A., Sjoberg, J., and Lundborg, G. (1989). Insulin-like growth factor I (IGF-I) stimulates regeneration of the rat sciatic nerve. Brain Res. 486, 396-398. doi: 10.1016/0006-8993(89)90531-3

Kanning, K. C., Kaplan, A., and Henderson, C. E. (2010). Motor neuron diversity in development and disease. Annu. Rev. Neurosci. 33, 409-440.

Kaplan, A., Spiller, K. J., Towne, C., Kanning, K. C., Choe, G. T., Geber, A., et al. (2014). Neuronal matrix metalloproteinase- 9 is a determinant of selective neurodegeneration. Neuron 81, 333-348. doi: 10.1016/j.neuron.2013. 12.009

Krieger, F., Elflein, N., Saenger, S., Wirthgen, E., Rak, K., Frantz, S., et al. (2014). Polyethylene glycol-coupled IGF-1 delays motor function defects in a mouse model of spinal muscular atrophy with respiratory distress type 1. Brain $137(\mathrm{Pt}$ 5), 1374-1393. doi: 10.1093/brain/awu059

Lai, E. C., Felice, K. J., Festoff, B. W., Gawel, M. J., Gelinas, D. F., Kratz, R., et al. (1997). Effect of recombinant human insulin-like growth factor-I on progression of ALS. A placebo-controlled study. The North America ALS/IGF-I study group. Neurology 49, 1621-1630. doi: 10.1212/wnl.49.6.1621

Landmesser, L., and Pilar, G. (1978). Interactions between neurons and their targets during in vivo synaptogenesis. Fed. Proc. 37, 2016-2022.

Lee, S., Lee, B., Lee, J. W., and Lee, S. K. (2009). Retinoid signaling and neurogenin2 function are coupled for the specification of spinal motor neurons through a chromatin modifier CBP. Neuron 62, 641-654. doi: 10.1016/j.neuron.2009.04. 025

Lodato, S., and Arlotta, P. (2015). Generating neuronal diversity in the mammalian cerebral cortex. Annu. Rev. Cell Dev. Biol. 31, 699-720. doi: 10.1146/annurevcellbio-100814-125353

Lodato, S., Shetty, A. S., and Arlotta, P. (2015). Cerebral cortex assembly: generating and reprogramming projection neuron diversity. Trends Neurosci. 38, 117-125. doi: 10.1016/j.tins.2014.11.003

Maasz, G., Zrinyi, Z., Reglodi, D., Petrovics, D., Rivnyak, A., Kiss, T., et al. (2017). Pituitary adenylate cyclase-activating polypeptide (PACAP) has a neuroprotective function in dopamine-based neurodegeneration in rat and snail parkinsonian models. Dis. Model Mech. 10, 127-139.

Manecka, D. L., Mahmood, S. F., Grumolato, L., Lihrmann, I., and Anouar, Y. (2013). Pituitary adenylate cyclase-activating polypeptide (PACAP) promotes both survival and neuritogenesis in PC12 cells through activation of nuclear factor kappaB (NF-kappaB) pathway: involvement of extracellular signalregulated kinase (ERK), calcium, and c-REL. J. Biol. Chem. 288, 14936-14948. doi: $10.1074 / j b c . m 112.434597$

Markram, H., Toledo-Rodriguez, M., Wang, Y., Gupta, A., Silberberg, G., and Wu, C. (2004). Interneurons of the neocortical inhibitory system. Nat. Rev. Neurosci. 5, 793-807. doi: $10.1038 / \mathrm{nrn} 1519$

Martinez-Rojas, V. A., Jimenez-Garduno, A. M., Michelatti, D., Tosatto, L., Marchioretto, M., Arosio, D., et al. (2021). ClC-2-like chloride current alterations in a cell model of spinal and bulbar muscular atrophy, a polyglutamine disease. J. Mol. Neurosci. 71, 662-674. doi: 10.1007/s12031-02001687-5

Maugeri, G., D’Amico, A. G., Rasa, D. M., Federico, C., Saccone, S., Morello, G., et al. (2019). Molecular mechanisms involved in the protective effect of pituitary adenylate cyclase-activating polypeptide in an in vitro model of amyotrophic lateral sclerosis. J. Cell. Physiol. 234, 5203-5214. doi: 10.1002/jcp.27 328

Mendell, J. R., Al-Zaidy, S., Shell, R., Arnold, W. D., Rodino-Klapac, L. R., Prior, T. W., et al. (2017). Single-dose gene-replacement therapy for spinal muscular atrophy. N. Engl. J. Med. 377, 1713-1722. doi: 10.1056/NEJMoa1706198

Miyata, A., Arimura, A., Dahl, R. R., Minamino, N., Uehara, A., Jiang, L., et al. (1989). Isolation of a novel 38 residue-hypothalamic polypeptide which stimulates adenylate cyclase in pituitary cells. Biochem. Biophys. Res. Commun. 164, 567-574. doi: 10.1016/0006-291X(89)91757-9

Molyneaux, B. J., Arlotta, P., Fame, R. M., MacDonald, J. L., MacQuarrie, K. L., and Macklis, J. D. (2009). Novel subtype-specific genes identify distinct subpopulations of callosal projection neurons. J. Neurosci. 29, 12343-12354. doi: 10.1523/JNEUROSCI.6108-08.2009

Molyneaux, B. J., Arlotta, P., Hirata, T., Hibi, M., and Macklis, J. D. (2005). Fezl is required for the birth and specification of corticospinal motor neurons. Neuron 47, 817-831. doi: 10.1016/j.neuron.2005.08.030

Muller, A. P., Fernandez, A. M., Haas, C., Zimmer, E., Portela, L. V., and TorresAleman, I. (2012). Reduced brain insulin-like growth factor I function during aging. Mol. Cell. Neurosci. 49, 9-12. doi: 10.1016/j.mcn.2011.07.008

Muller, D., Cherukuri, P., Henningfeld, K., Poh, C. H., Wittler, L., Grote, P., et al. (2014). Dlk1 promotes a fast motor neuron biophysical signature required for peak force execution. Science 343, 1264-1266. doi: 10.1126/science.1246448

Nagano, I., Shiote, M., Murakami, T., Kamada, H., Hamakawa, Y., Matsubara, E., et al. (2005). Beneficial effects of intrathecal IGF-1 administration in patients with amyotrophic lateral sclerosis. Neurol. Res. 27, 768-772. doi: 10.1179/ $016164105 X 39860$

Nakao, Y., Otani, H., Yamamura, T., Hattori, R., Osako, M., and Imamura, H. (2001). Insulin-like growth factor 1 prevents neuronal cell death and paraplegia in the rabbit model of spinal cord ischemia. J. Thorac. Cardiovasc. Surg. 122, 136-143. doi: 10.1067/mtc.2001.114101

Nijssen, J., Comley, L. H., and Hedlund, E. (2017). Motor neuron vulnerability and resistance in amyotrophic lateral sclerosis. Acta Neuropathol. 133, 863-885. doi: 10.1007/s00401-017-1708-8

Novitch, B. G., Chen, A. I., and Jessell, T. M. (2001). Coordinate regulation of motor neuron subtype identity and pan-neuronal properties by the bHLH repressor Olig2. Neuron 31, 773-789. doi: 10.1016/S0896-6273(01)00407-X

Oberbauer, A. M. (2013). The regulation of IGF-1 gene transcription and splicing during development and aging. Front. Endocrinol. 4:39. doi: 10.3389/fendo. 2013.00039

Ogata, K., Shintani, N., Hayata-Takano, A., Kamo, T., Higashi, S., Seiriki, K., et al. (2015). PACAP enhances axon outgrowth in cultured hippocampal neurons to a comparable extent as BDNF. PLoS One 10:e0120526. doi: 10.1371/journal.pone. 0120526

Palazzolo, I., Burnett, B. G., Young, J. E., Brenne, P. L., La Spada, A. R., Fischbeck, K. H., et al. (2007). Akt blocks ligand binding and protects against expanded polyglutamine androgen receptor toxicity. Hum. Mol. Genet. 16, 1593-1603. doi: $10.1093 / \mathrm{hmg} / \mathrm{ddm} 109$

Palazzolo, I., Stack, C., Kong, L., Musaro, A., Adachi, H., Katsuno, M., et al. (2009). Overexpression of IGF-1 in muscle attenuates disease in a mouse model of spinal and bulbar muscular atrophy. Neuron 63, 316-328. doi: 10.1016/j. neuron.2009.07.019

Passini, M. A., Bu, J., Richards, A. M., Kinnecom, C., Sardi, S. P., Stanek, L. M., et al. (2011). Antisense oligonucleotides delivered to the mouse CNS ameliorate symptoms of severe spinal muscular atrophy. Sci. Transl. Med. 3:72ra18. doi: 10.1126/scitranslmed.3001777

Pettersson, L. M., Geremia, N. M., Ying, Z., and Verge, V. M. (2014). Injuryassociated PACAP expression in rat sensory and motor neurons is induced by endogenous BDNF. PLoS One 9:e100730. doi: 10.1371/journal.pone.0100730

Polanco, M. J., Parodi, S., Piol, D., Stack, C., Chivet, M., Contestabile, A., et al. (2016). Adenylyl cyclase activating polypeptide reduces phosphorylation and toxicity of the polyglutamine-expanded androgen receptor in spinobulbar muscular atrophy. Sci. Transl. Med. 8:370ra181. doi: 10.1126/scitranslmed. aaf 9526

Rat, D., Schmitt, U., Tippmann, F., Dewachter, I., Theunis, C., Wieczerzak, E., et al. (2011). Neuropeptide pituitary adenylate cyclase-activating polypeptide (PACAP) slows down Alzheimer's disease-like pathology in amyloid precursor protein-transgenic mice. FASEB J. 25, 3208-3218. doi: 10.1096/ff.10-180133

Rinaldi, C., Bott, L. C., Chen, K. L., Harmison, G. G., Katsuno, M., Sobue, G., et al. (2012). IGF-1 administration ameliorates disease manifestations in a mouse model of spinal and bulbar muscular atrophy. Mol. Med. 18, 1261-1268. doi: 10.2119/molmed.2012.00271

Ringer, C., Buning, L. S., Schafer, M. K., Eiden, L. E., Weihe, E., and Schutz, B. (2013). PACAP signaling exerts opposing effects on neuroprotection and neuroinflammation during disease progression in the SOD1(G93A) mouse model of amyotrophic lateral sclerosis. Neurobiol. Dis. 54, 32-42. doi: 10.1016/ j.nbd.2013.02.010

Rotwein, P., Burgess, S. K., Milbrandt, J. D., and Krause, J. E. (1988). Differential expression of insulin-like growth factor genes in rat central nervous system. Proc. Natl. Acad. Sci. U.S.A. 85, 265-269. doi: 10.1073/pnas.85.1.265 
Saenger, S., Holtmann, B., Nilges, M. R., Schroeder, S., Hoeflich, A., Kletzl, H., et al. (2012). Functional improvement in mouse models of familial amyotrophic lateral sclerosis by PEGylated insulin-like growth factor I treatment depends on disease severity. Amyotroph. Lateral Scler. 13, 418-429. doi: 10.3109/17482968. 2012.679944

Salmon, W. D. Jr., and Daughaday, W. H. (1957). A hormonally controlled serum factor which stimulates sulfate incorporation by cartilage in vitro. J. Lab. Clin. Med. 49, 825-836.

Shneider, N. A., Brown, M. N., Smith, C. A., Pickel, J., and Alvarez, F. J. (2009). Gamma motor neurons express distinct genetic markers at birth and require muscle spindle-derived GDNF for postnatal survival. Neural Dev. 4:42. doi: 10.1186/1749-8104-4-42

Soles-Tarres, I., Cabezas-Llobet, N., Vaudry, D., and Xifro, X. (2020). Protective effects of pituitary adenylate cyclase-activating polypeptide and vasoactive intestinal peptide against cognitive decline in neurodegenerative diseases. Front. Cell. Neurosci. 14:221. doi: 10.3389/fncel.2020.00221

Sorenson, E. J., Windbank, A. J., Mandrekar, J. N., Bamlet, W. R., Appel, S. H., Armon, C., et al. (2008). Subcutaneous IGF-1 is not beneficial in 2year ALS trial. Neurology 71, 1770-1775. doi: 10.1212/01.wnl.0000335970.786 64.36

Ster, J., De Bock, F., Guerineau, N. C., Janossy, A., Barrere-Lemaire, S., Bos, J. L., et al. (2007). Exchange protein activated by cAMP (Epac) mediates cAMP activation of p38 MAPK and modulation of Ca2+-dependent $\mathrm{K}+$ channels in cerebellar neurons. Proc. Natl. Acad. Sci. U.S.A. 104, 2519-2524. doi: 10.1073/ pnas.0611031104

Stifani, N. (2014). Motor neurons and the generation of spinal motor neuron diversity. Front. Cell. Neurosci. 8:293. doi: 10.3389/fncel.2014.00293

Stroth, N., Kuri, B. A., Mustafa, T., Chan, S. A., Smith, C. B., and Eiden, L. E. (2013). PACAP controls adrenomedullary catecholamine secretion and expression of catecholamine biosynthetic enzymes at high splanchnic nerve firing rates characteristic of stress transduction in male mice. Endocrinology 154, 330-339. doi: 10.1210/en.2012-1829

Toth, P., Tarantini, S., Ashpole, N. M., Tucsek, Z., Milne, G. L., Valcarcel-Ares, N. M., et al. (2015). IGF-1 deficiency impairs neurovascular coupling in mice: implications for cerebromicrovascular aging. Aging Cell 14, 1034-1044. doi: 10.1111/acel.12372

Tsai, L. K., Chen, C. L., Ting, C. H., Lin-Chao, S., Hwu, W. L., Dodge, J. C., et al. (2014). Systemic administration of a recombinant AAV1 vector encoding IGF1 improves disease manifestations in SMA mice. Mol. Ther. 22, 1450-1459. doi: 10.1038/mt.2014.84

Tsuchida, M., Nakamachi, T., Sugiyama, K., Tsuchikawa, D., Watanabe, J., Hori, M., et al. (2014). PACAP stimulates functional recovery after spinal cord injury through axonal regeneration. J. Mol. Neurosci. 54, 380-387. doi: 10.1007/ s12031-014-0338-z
Vallstedt, A., Muhr, J., Pattyn, A., Pierani, A., Mendelsohn, M., Sander, M., et al. (2001). Different levels of repressor activity assign redundant and specific roles to Nkx6 genes in motor neuron and interneuron specification. Neuron 31, 743-755. doi: 10.1016/S0896-6273(01)00412-3

Vincent, A. M., Mobley, B. C., Hiller, A., and Feldman, E. L. (2004). IGF-I prevents glutamate-induced motor neuron programmed cell death. Neurobiol. Dis. 16, 407-416. doi: 10.1016/j.nbd.2004.03.001

Wang, W., Wen, D., Duan, W., Yin, J., Cui, C., Wang, Y., et al. (2018). Systemic administration of scAAV9-IGF-1 extends survival in SOD1(G93A) ALS mice via inhibiting p38 MAPK and the JNK-mediated apoptosis pathway. Brain Res. Bull. 139, 203-210. doi: 10.1016/j.brainresbull.2018.02.015

Writing Group; Edaravone (MCI-186) ALS 19 Study Group (2017). Safety and efficacy of edaravone in well defined patients with amyotrophic lateral sclerosis: a randomised, double-blind, placebo-controlled trial. Lancet Neurol. 16, 505512. doi: 10.1016/S1474-4422(17)30115-1

Yang, L., Wang, H., Liu, L., and Xie, A. (2018). The role of insulin/IGF1/PI3K/Akt/GSK3beta signaling in Parkinson's disease dementia. Front. Neurosci. 12:73. doi: 10.3389/fnins.2018.00073

Ye, P., Li, L., Lund, P. K., and D’Ercole, A. J. (2002). Deficient expression of insulin receptor substrate-1 (IRS-1) fails to block insulin-like growth factor-I (IGF-I) stimulation of brain growth and myelination. Brain Res. Dev. Brain Res. 136, 111-121. doi: 10.1016/S0165-3806(02)00355-3

Zhou, C. J., Shioda, S., Shibanuma, M., Nakajo, S., Funahashi, H., Nakai, Y., et al. (1999). Pituitary adenylate cyclase-activating polypeptide receptors during development: expression in the rat embryo at primitive streak stage. Neuroscience 93, 375-391. doi: 10.1016/S0306-4522(99) 00108-6

Conflict of Interest: The authors declare that the research was conducted in the absence of any commercial or financial relationships that could be construed as a potential conflict of interest.

Publisher's Note: All claims expressed in this article are solely those of the authors and do not necessarily represent those of their affiliated organizations, or those of the publisher, the editors and the reviewers. Any product that may be evaluated in this article, or claim that may be made by its manufacturer, is not guaranteed or endorsed by the publisher.

Copyright (C) 2021 Zuccaro, Piol, Basso and Pennuto. This is an open-access article distributed under the terms of the Creative Commons Attribution License (CC BY). The use, distribution or reproduction in other forums is permitted, provided the original author(s) and the copyright owner(s) are credited and that the original publication in this journal is cited, in accordance with accepted academic practice. No use, distribution or reproduction is permitted which does not comply with these terms. 